\title{
Effect of Tentoxin on the Activation and on the Catalytic Reaction of Reconstituted $\mathrm{H}^{+}$-ATPase from Chloroplasts
}

\author{
Petra Fromme \\ Max-Volmer-Institut für Biophysikalische und Physikalische Chemie, \\ Technische Universität Berlin, Straße des 17. Juni 135, \\ D-W-1000 Berlin 12, Bundesrepublik Deutschland \\ Ingo Dahse \\ Friedrich-Schiller-Universität Jena, Biologische Fakultät, \\ Institut für Biochemie und Biophysik, Philosophenweg 12, \\ D-O-6900 Jena, Bundesrepublik Deutschland \\ and \\ Peter Gräber \\ Biologisches Institut, Universität Stuttgart, Pfaffenwaldring 57, \\ D-W-7000 Stuttgart 60, Bundesrepublik Deutschland \\ Z. Naturforsch. 47 c, 239-244 (1992); received September 30, 1991/January 3, 1992 \\ $\mathrm{H}^{+}$-ATPase, $\mathrm{CF}_{0} \mathrm{~F}_{1}$, Tentoxin, Enzyme Kinetics, Uni-Site Catalysis \\ The proton-translocating ATPase from chloroplasts, $\mathrm{CF}_{0} \mathrm{~F}_{1}$, was isolated, purified and re- \\ constituted into asolectin liposomes. The effect of the energy transfer inhibitor, tentoxin, on \\ different functions of the enzyme was investigated. Tentoxin does not inhibit the nucleotide \\ release during energization by a $\mathrm{pH} / \Delta \Psi$ jump, i.e. the activation of the enzyme is not influ- \\ enced. ATP synthesis driven by a $\mathrm{pH} / \Delta \Psi$ jump and multi-site ATP hydrolysis are completely \\ inhibited by tentoxin, whereas uni-site ATP hydrolysis is not influenced.
}

\section{Introduction}

Membrane-bound $\mathrm{H}^{+}$-ATPases of the $\mathrm{F}_{0} \mathrm{~F}_{1}$-type catalyze ATP synthesis/hydrolysis coupled with a transmembrane proton transport. These ATPases have a hydrophilic part, $F_{1}$, containing the nucleotide-binding sites and a hydrophobic membraneintegrated part, $\mathrm{F}_{0}$, functioning as a proton channel. The $F_{1}$ part has six nucleotide-binding sites. Three of them are supposed to have catalytic properties, i.e. they can hydrolyze ATP [1-4]. The phytotoxin, tentoxin [cyclo(L-leucyl-N-methyl- $(Z)$ dehydrophenylalanyl-glycyl-N-methyl-L-alanyl)], produced by the fungus Alternaria alternata (=A.tenuis; $[5,6])$, binds to a site on the $\alpha$ and/or $\beta$ subunits of the $\mathrm{CF}_{1}$ part [7]. At low concentrations between 0.1 and $1 \mu \mathrm{M}$ (at a tentoxin: enzyme ratio of $10: 1)$ tentoxin is a non-competitive inhibitor of the enzyme [8]; at high concentrations

Abbreviation: $\mathrm{CF}_{0} \mathrm{~F}_{1}, \mathrm{H}^{+}$-ATPase (ATP synthase) from chloroplasts.

Reprint requests to Dr. P. Fromme.

Verlag der Zeitschrift für Naturforschung,

D-W-7400 Tübingen

$0939-5075 / 92 / 0300-0239 \$ 01.30 / 0$
(10 $\mu \mathrm{M}$ to $1 \mathrm{~mm}$ ) it is able to stimulate ATP hydrolysis activity of the isolated $\mathrm{CF}_{1}[9-11]$. It has been shown by Junge et al. [12] that inhibition of photophosphorylation by tentoxin is accompanied by the cessation of the phosphorylation-coupled proton efflux through ATPase. This explains the slower relaxation of light-induced transmembrane electric potential difference and the enhanced delayed fluorescence which were observed with tentoxintreated chloroplasts [13-15]. The specificity of tentoxin action prompted us to investigate its effect on the isolated, reconstituted $\mathrm{CF}_{0} \mathrm{~F}_{1}$.

\section{Materials and Methods}

\section{Isolation and reconstitution of $C F_{0} F_{l}$}

$\mathrm{CF}_{0} \mathrm{~F}_{1}$ was isolated from spinach chloroplasts, purified and reconstituted into asolectin liposomes by cholate dialysis as described earlier [16-18]. The proteoliposomes finally contained approximately $1 \mu \mathrm{M} C \mathrm{CF}_{0} \mathrm{~F}_{1}$ and $30 \mathrm{~g} / 1$ asolectin, $10 \mathrm{~mm}$ Na-Tricine, pH 8.0, 0.2 mм EDTA, $2.5 \mathrm{~mm} \mathrm{MgCl}_{2}$ and $0.25 \mathrm{~mm}$ dithiothreitol. Prior to every set of experiments the enzyme was reduced in the presence of dithiothreitol and then activated by a $\mathrm{pH} / \Delta \Psi$ jump as described earlier [19]. 


\section{Reduction of $C F_{0} F_{l}$ in proteoliposomes}

The proteoliposomes were incubated for $1.5 \mathrm{~h}$ with $50 \mathrm{~mm}$ dithiothreitol at $\mathrm{pH} 8.0$ at room temperature.

\section{Incubation with tentoxin}

The reduced proteoliposomes $\left(\left[\mathrm{CF}_{0} \mathrm{~F}_{1}\right]=1 \mu \mathrm{M}\right)$ were incubated with tentoxin before every set of experiments: an aqueous solution of tentoxin (1 mM) was stored at $-20{ }^{\circ} \mathrm{C}$ and freshly diluted to appropriate concentrations. Then $2 \mu \mathrm{l}$ of this solution were added to the five-fold volume of reduced proteoliposomes and incubated for the time indicated.

\section{Activation of reduced $C F_{0} F_{1}$}

After preincubation of proteoliposomes with tentoxin, $\mathrm{CF}_{0} \mathrm{~F}_{1}$ was activated by a $\mathrm{pH} / \Delta \Psi$ jump $(\Delta \mathrm{pH}=3.2, \Delta \Psi=60 \mathrm{mV})$ as follows: $10 \mu \mathrm{l}$ of the proteoliposome solution were added to $50 \mu$ of the acidic solution (buffer 1) containing $30 \mathrm{~mm}$ Na-succinate ( $\mathrm{pH}$ 4.9), $5 \mathrm{~mm} \mathrm{NaH} \mathrm{PO}_{4}, 2 \mathrm{~mm}$ $\mathrm{MgCl}_{2}, 0.5 \mathrm{~mm} \mathrm{KCl}$ and $1 \mu \mathrm{M}$ of freshly added valinomycin. The $\mathrm{pH}$ during incubation was 5.0. After $30 \mathrm{~s}$ of incubation, $50 \mu \mathrm{l}$ of an alkaline solution (buffer 2) consisting of $200 \mathrm{~mm} \mathrm{Na-Tricine}(\mathrm{pH}$ 8.7), $120 \mathrm{~mm} \mathrm{KCl}, 5 \mathrm{~mm} \mathrm{NaH} \mathrm{PO}_{4}$ and $2 \mathrm{~mm}$ $\mathrm{MgCl}_{2}$ were added. The final $\mathrm{pH}$ was 8.2.

The acidic and the alkaline solutions both contained the same tentoxin concentration as was used for the preincubation, because tentoxin effect is reversible [9]. Fifteen seconds after the $\mathrm{pH} / \Delta \Psi$ jump, $75 \mu \mathrm{l}$ of the reaction sample were used for the determination of ATP and for the sum of ADP and ATP by luciferin/luciferase in two separate assays as described elsewhere [19]. In order to obtain samples without activation of $\mathrm{CF}_{0} \mathrm{~F}_{1}$ the acidic and alkaline solution were mixed before addition of proteoliposomes.

\section{Synthesis of ATP in a $\mathrm{pH} / \Delta \Psi$ jump ( ATP yield)}

The acid-base transition was carried out as described for activation except that $200 \mu \mathrm{M}$ ADP were present in the alkaline solution (buffer 3). Fifteen seconds after the acid-base transition, the reaction was stopped by the addition of trichloroacetic acid (final concentration $2 \% \mathrm{w} / \mathrm{v}$ ). Ten $\mu$ l of this solution was used for the determination of
ATP with luciferin/luciferase as described elsewhere [19]. The ATP background was determined by mixing the acidic and alkaline solutions before the addition of proteoliposomes; fifteen seconds after this addition the sample was denatured and ATP content was determined as previously described. This background was always subtracted.

\section{Uni-site ATP hydrolysis}

The enzyme was incubated with tentoxin $(1 \mu \mathrm{M}$ $\mathrm{CF}_{0} \mathrm{~F}_{1}, 4 \mu \mathrm{M}$ tentoxin) for $10 \mathrm{~min}$ and then activated as described above. Fifteen seconds after the $\mathrm{pH} / \Delta \Psi$ jump, $40 \mathrm{~nm} \mathrm{Mg-ATP}$ and $10 \mathrm{~mm} \mathrm{NH}_{4} \mathrm{Cl}$ were added in a solution identical to the reaction medium. At different reaction times $75 \mu \mathrm{l}$ samples were taken to determine the free concentration of ATP or the sum of ATP and ADP with luciferin/ luciferase.

\section{Multi-site ATP hydrolysis}

The enzyme was activated as described above. Mg-ATP labeled in the $\gamma$-position with ${ }^{32} \mathrm{P}$ ( $30 \mathrm{kBq}$; final concentration $10 \mu \mathrm{M}$ to $1 \mathrm{~mm}$ ) was added fifteen seconds after the $\mathrm{pH} / \Delta \Psi$ jump in a solution identical with the reaction medium but containing in addition $10 \mathrm{~mm} \mathrm{NH} \mathrm{NH}_{4} \mathrm{Cl}$. At reaction times between 10 and 30 seconds samples were taken and denatured with $3 \%$ trichloro-acetic acid (final concentration). The ${ }^{32} \mathrm{P}_{\mathrm{i}}$ content of the samples was determined as described elsewhere [19].

\section{Results and Discussion}

$\mathrm{CF}_{0} \mathrm{~F}_{1}$ can exist in four different states, oxidized and reduced and both active or inactive. After reconstitution the enzyme is in the oxidized, inactive state. The inactive enzyme is unable to catalyze ATP hydrolysis or ATP synthesis. The isolated, reconstituted enzyme contains 1 ADP and 1 ATP per $\mathrm{CF}_{0} \mathrm{~F}_{1}$. The ATP can be released only by denaturating the enzyme. The ADP is released during activation. If the enzyme is activated by a $\mathrm{pH} / \Delta \Psi$ jump in the presence of phosphate, the ADP is partly phosphorylated to ATP when the membrane is energized (about $1-2 \mathrm{sec}$; [20]). Therefore, the total amount of nucleotides (ADP + ATP) released indicates the amount of the active enzyme. About $20-30 \%$ of the total $\mathrm{CF}_{0} \mathrm{~F}_{1}$ can be activated [19]. 


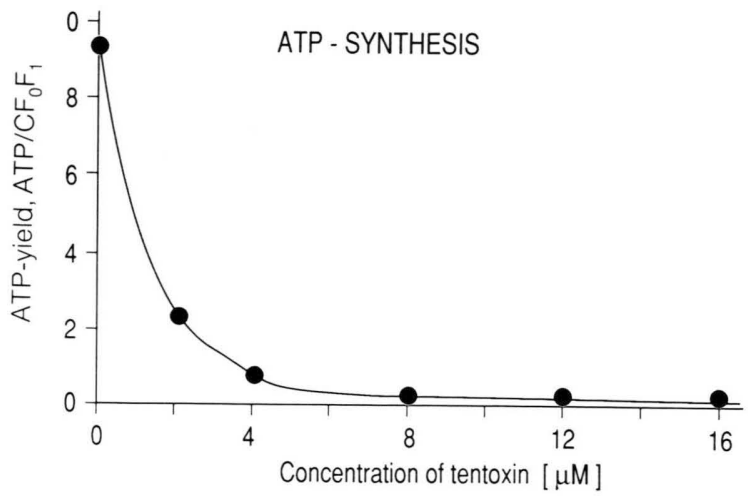

Fig. 1. ATP synthesis by $\mathrm{CF}_{0} \mathrm{~F}_{1}(1 \mu \mathrm{M})$ reconstituted into proteoliposomes: The ATP yield in a $\mathrm{pH} / \Delta \Psi$ jump is shown as a function of tentoxin concentration. Preincubation medium ( $5 \mathrm{~min}$ ) and reaction medium contain the same concentration of tentoxin.

Fig. 1 shows ATP synthesis by proteoliposomes in a $\mathrm{pH} / \Delta \Psi$ jump as a function of the tentoxin concentration. The proteoliposomes were preincubated for $5 \mathrm{~min}$ with the indicated tentoxin concentration and then the $\mathrm{pH} / \Delta \Psi$ jump was carried out (see Materials and Methods). The ATP yield decreased rapidly and at $8 \mu \mathrm{M}$ tentoxin (at a tentoxin: $\mathrm{CF}_{0} \mathrm{~F}_{1}$ ratio of $8: 1$ ), no further ATP synthesis was measured. It should be mentioned that the inhibition of ATP hydrolysis catalyzed by trypsin-treated $\mathrm{CF}_{1}$ occurred at a ratio of tentoxin: enzyme of $10: 1[10]$.

Here the question is addressed in which step of catalysis is tentoxin involved. Does it inhibit the activation of the enzyme, or one step in the catalytic turnover of the enzyme (substrate binding, catalytic reaction $\mathrm{ATP} \leftrightarrow \mathrm{ADPP}_{\mathrm{i}}$ on the enzyme, product release) or the cooperativity between the sites?

For this purpose the fraction of active $\mathrm{CF}_{0} \mathrm{~F}_{1}$ was measured as a function of the preincubation time with tentoxin. The experiment was carried out as follows: the proteoliposomes were incubated with $2 \mu \mathrm{M}$ tentoxin for different times. Then, $\mathrm{CF}_{0} \mathrm{~F}_{1}$ was activated by a $\mathrm{pH} / \Delta \Psi$ jump in the absence of exogenous ADP. In two separate experiments free ATP and the sum of free ADP and ATP was determined. As the control the same experiments were carried out without a $\mathrm{pH} / \Delta \Psi$ jump. The result is shown in Fig. 2:

(A) About 0.2 free nucleotides (ATP + ADP) per $\mathrm{CF}_{0} \mathrm{~F}_{1}$ were found after $\mathrm{pH} / \Delta \Psi$ jump and this amount does not depend on the incubation time with tentoxin.

(B) The amount of free ATP per $\mathrm{CF}_{0} \mathrm{~F}_{1}$ after the $\mathrm{pH} / \Delta \Psi$ jump decreases from 0.06 to 0.01 ATP per $\mathrm{CF}_{0} \mathrm{~F}_{1}$ during incubation with tentoxin, i.e. the ratio between free ADP and free ATP changed although the total amount of nucleotides remained constant.

(C) Without an activating $\mathrm{pH} / \Delta \Psi$ jump the amount of free nucleotides (ATP + ADP) is 0.05 per $\mathrm{CF}_{0} \mathrm{~F}_{1}$ and does not depend on incubation time with tentoxin.

(D) Almost no free ATP is detected without $\mathrm{pH} / \Delta \Psi$ jump.

(E) For comparison the ATP yield in the presence of $100 \mu \mathrm{M}$ ADP was measured with the same $\mathrm{pH} / \Delta \Psi$ jump as a function of incubation time with tentoxin (dashed curve, scale on the right side). The ATP yield decreased continuously with increasing incubation time.

These results lead us to the following conclusions:

(1) The nucleotide release induced by energization of the membrane is not influenced by incubation with tentoxin. Since the ADP release from $\mathrm{CF}_{0} \mathrm{~F}_{1}$ upon energization is related to the activa-

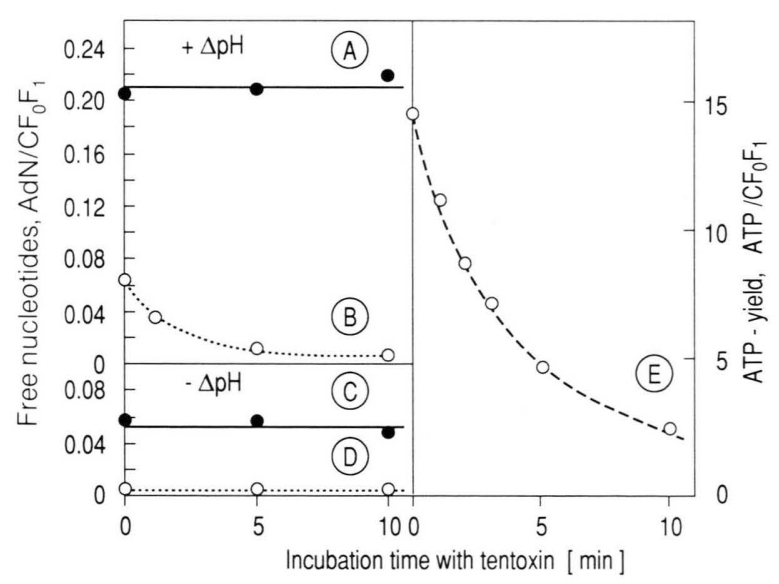

Fig. 2. Influence of tentoxin on ATP synthesis and nucleotide release during activation. The proteoliposomes $\left(\left[\mathrm{CF}_{0} \mathrm{~F}_{1}\right]=1 \mu \mathrm{M}\right)$ were incubated with $2 \mu \mathrm{M}$ tentoxin for the time indicated. Then the following measurements were carried out in the presence of $2 \mu \mathrm{M}$ tentoxin: (A) The sum of free (ATP + ADP) $/ \mathrm{CF}_{0} \mathrm{~F}_{1}$ after a $\mathrm{pH} / \Delta \Psi$ jump. (B) Free ATP $/ \mathrm{CF}_{0} \mathrm{~F}_{1}$ (after a $\mathrm{pH} / \Delta \Psi$ jump). (C) The sum of free $(\mathrm{ATP}+\mathrm{ADP}) / \mathrm{CF}_{0} \mathrm{~F}_{1}$ (without $\mathrm{pH} / \Delta \Psi$ jump). (D) Free ATP $/ \mathrm{CF}_{0} \mathrm{~F}_{1}$ (without $\mathrm{pH} / \Delta \Psi$ jump). (E) ATP yield in a $\mathrm{pH} / \Delta \Psi$ jump. 
tion, this result shows that tentoxin does not change the fraction of the activated enzyme.

(2) A part of the released ADP is re-bound and phosphorylated to ATP during the $\mathrm{pH}$ jump. This part decreases during incubation with tentoxin indicating that the catalytic process is inhibited. The ATP yield measured in the same type of experiment decreases in parallel and supports this conclusion.

(3) The ATP yield (curve E) was measured in the presence of $100 \mu \mathrm{M}$ ADP and therefore, all accessible ADP-binding sites are involved (multi-site ATP synthesis). The amount of ATP generated in the experiment (B) was measured under uni-site conditions since the concentration of free ADP was much lower than the enzyme concentration (uni-site ATP synthesis). Therefore, multi-site and uni-site ATP synthesis are inhibited by tentoxin.

(4) Tentoxin $\left(2 \mu \mathrm{M}\right.$; tentoxin: $\left.\mathrm{CF}_{0} \mathrm{~F}_{1}=2: 1\right)$ does not itself induce a release of tightly bound nucleotides (Fig. 2C and D). Therefore, we conclude that at this low concentration no tentoxin-induced activation of the enzyme occurs.

At high tentoxin concentration $(400 \mu \mathrm{M})$ the ATPase activity of isolated $\mathrm{CF}_{1}$ was stimulated and can be correlated to the release of tightly bound nucleotides [9, 21]. This stimulatory effect by high tentoxin concentration can, therefore, be explained by the release of tightly bound ADP from the regulatory site activating the $\mathrm{CF}_{1}$.

In the next experiment the effect of tentoxin on uni-site ATP hydrolysis was measured. $\mathrm{CF}_{0} \mathrm{~F}_{1}$ was activated by a $\mathrm{pH} / \Delta \Psi$ jump and ATP was added, so that the initial concentration of ATP was $50 \mathrm{nM}$. The concentration of ATP and that of (ADP + ATP) was measured. Fig. 3 shows the result: ATP was bound to the enzyme and with almost the same kinetics ADP was released.

From this measurement the rate constant for ATP binding was determined to be $1 \times 10^{6} \mathrm{M}^{-1} \mathrm{~s}^{-1}$. This is the same number as found in the absence of tentoxin. In addition, the ADP release is the same in the presence and absence of tentoxin [19]. Therefore, we have to conclude that neither ATPbinding, nor ATP hydrolysis on the enzyme nor release of ADP is affected by tentoxin.

In the next experiments the influence of tentoxin on the rate of ATP hydrolysis was measured at concentrations of ATP from $10 \mu \mathrm{M}$ to $1 \mathrm{~mm}$ where multi-site hydrolysis occurs. First, the rate of ATP

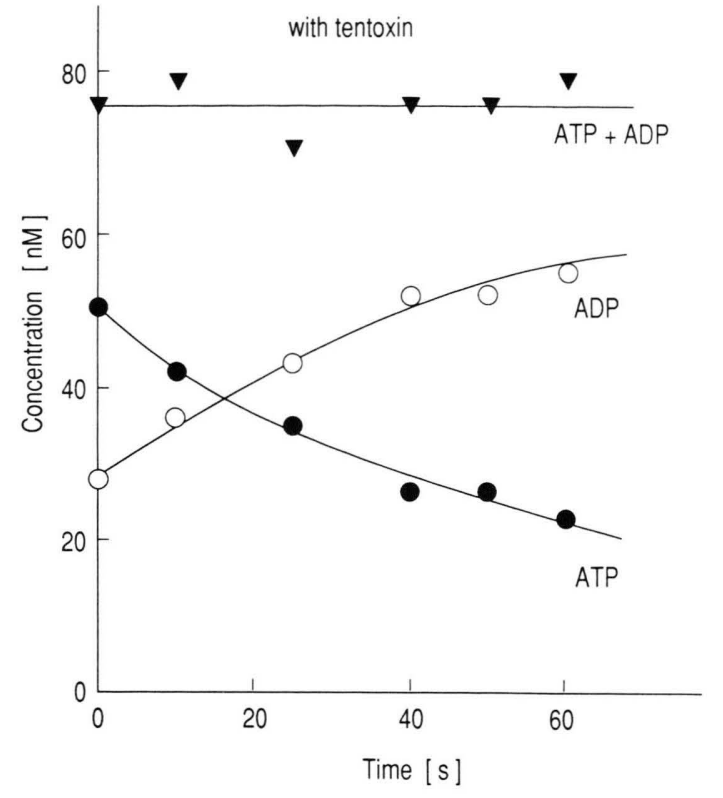

Fig. 3. Single-site ATP hydrolysis: The proteoliposomes $\left(\left[\mathrm{CF}_{0} \mathrm{~F}_{1}\right]=1 \mu \mathrm{M}\right)$ were preincubated with $4 \mu \mathrm{M}$ tentoxin for $10 \mathrm{~min}$. Then, the enzyme was activated by a $\mathrm{pH} / \Delta \Psi$ jump and ATP was added. During the reaction $4 \mu \mathrm{M}$ tentoxin was present. The concentration of free ATP and the sum of free (ATP + ADP) were measured as a function of reaction time. The concentration of free ADP was calculated from the difference between both measurements.

hydrolysis was measured without tentoxin. The results are shown in Fig. 4. The rate increases with increasing ATP concentration. A LineweaverBurk plot of these data gives a $K_{\mathrm{M}}=180 \mu \mathrm{M}$ and $V_{\max }=58 \mathrm{ATP} /\left(\mathrm{CF}_{0} \mathrm{~F}_{1} \times \mathrm{s}\right)$. For investigation of

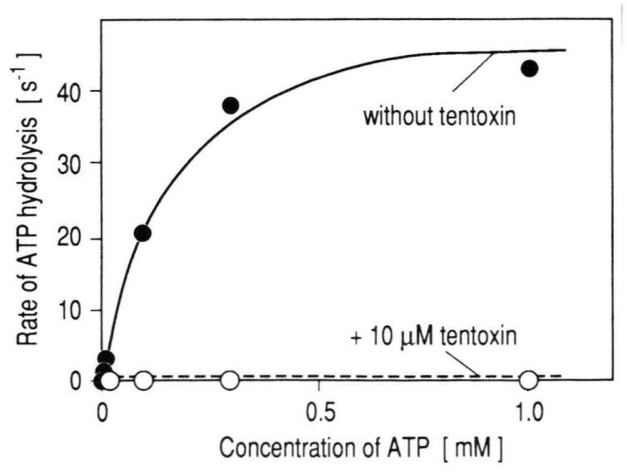

Fig. 4. Rate of ATP hydrolysis as a function of the ATP concentration. $\mathrm{CF}_{0} \mathrm{~F}_{1}(1.4 \mu \mathrm{M})$ was preincubated either without or with $10 \mu \mathrm{M}$ tentoxin for $10 \mathrm{~min}$, then the enzyme was activated by a $\mathrm{pH} / \Delta \Psi$ jump and the reaction was started by addition of $\gamma-\left[{ }^{32} \mathrm{P}\right]-\mathrm{ATP}$ and $10 \mathrm{~mm}$ $\mathrm{NH}_{4} \mathrm{Cl}$ (final concentration). 
the tentoxin effect the enzyme $\left(\left[\mathrm{CF}_{0} \mathrm{~F}_{1}\right]=1.4 \mu \mathrm{M}\right)$ was preincubated for $10 \mathrm{~min}$ with $10 \mu \mathrm{M}$ tentoxin. At this concentration ATP synthesis is completely blocked (Fig. 1). In the presence of tentoxin no ATP hydrolysis could be detected, i.e. tentoxin completely inhibits multi-site ATP hydrolysis.

These results can be summarized as follows. (1) Tentoxin does not change the fraction of activated $\mathrm{CF}_{0} \mathrm{~F}_{1}$. (2) In the presence of tentoxin neither multi-site nor uni-site ATP synthesis occurs. (3) Under uni-site conditions ATP binding, hydrolysis of ATP to enzyme-bound $\mathrm{ADPP}_{\mathrm{i}}$ and the release of ADP are not inhibited by tentoxin. (4) Tentoxin completely inhibits multi-site ATP hydrolysis.

The differential inhibition of uni-site and multisite ATP hydrolysis can be explained in two ways. (1) The $P_{i}$ release could be inhibited by tentoxin. In this case all reaction steps before the $\mathrm{P}_{\mathrm{i}}$ release can occur, however, only one turnover of the reaction is possible since the free enzyme is not regenerated. Therefore, several turnovers under uni-site conditions and multi-site ATP hydrolysis are inhibited. (2) Uni-site ATP hydrolysis is not inhibited but the cooperativity between different catalytic sites is prevented by tentoxin. This suggestion is supported by measurements of the differential effect of acid inactivation on uni-site and multi-site ATP hydrolysis [22].

Fig. 2 and Fig. 3 show that also uni-site ATP hydrolysis and uni-site ATP synthesis are differently affected by tentoxin. There are several possibilities to interpret this observation.

1) Uni-site ATP synthesis and uni-site ATP hydrolysis occur at different sites, e.g. the ATP synthesis is coupled with proton translocation, the ATP hydrolysis is not (as for example in $\mathrm{CF}_{1}$-catalyzed ATP hydrolysis).

2) Uni-site ATP synthesis and hydrolysis occur at the same site but tentoxin inhibits the conformational change which is necessary to couple proton transport through $\mathrm{CF}_{0}$ with the chemical reaction in $\mathrm{CF}_{1}$. Also in this case, uncoupled uni-site hydrolysis can occur but synthesis is inhibited.

3) If uni-site ATP synthesis and ATP hydrolysis occur via the same reaction pathway (microreversibility), both directions must be inhibited to the same extent. The measurements in this part (with the exception of Fig. 2E) are carried out under conditions where only a part of the enzymes carries out one turnover ("single turnover" conditions). If e.g. tentoxin inhibits the conformational change connected with proton transport (this is the first step of the ATP synthesis direction), then ATP synthesis will be completely blocked. However, the first steps of proton transport-coupled ATP hydrolysis can occur (e.g. ATP binding etc.) up to that step where coupling to proton transport must take place. In fact the enzyme is completely inhibited, however, this does not influence the first steps. In order to show this, the enzyme must carry out at least one turnover under uni-site conditions. As yet, we cannot decide between these possibilities.

The dependence of the fraction of activated $\mathrm{CF}_{0} \mathrm{~F}_{1}$ and the catalytic reaction of $\mathrm{CF}_{0} \mathrm{~F}_{1}$ on $\mathrm{pH} / \Delta \Psi[23]$ showed that both processes are driven by the transmembrane electrochemical potential difference of protons. Our results demonstrate that ATP synthesis was completely blocked by tentoxin, whereas the fraction of activated enzymes was not affected. Therefore, we have to assume that for activation of $\mathrm{CF}_{0} \mathrm{~F}_{1}$ and the catalytic reaction different pathways for protons should exist.

\section{Acknowledgements}

We thank Dr. B. Liebermann, Jena, for his generous donation of tentoxin. This work was supported by the Deutsche Forschungsgemeinschaft (Sfb 312). 
[1] R. L. Cross and C. M. Nalin, J. Biol. Chem. 257, 2874-2881 (1982).

[2] J. Weber, U. Lücken, and G. Schäfer, Eur. J. Biochem. 148, 41-47 (1985).

[3] F. A. S. Kironde and R. L. Cross, J. Biol. Chem. 261, 12544-12549 (1986).

[4] K. M. Musier and G. G. Hammes, Biochemistry 27, 7015-7020 (1988).

[5] N. D. Fulton, K. Bollenbacher, and G. E. Templeton, Phytopathology 55, 49-51 (1965).

[6] W. L. Meyer, L. F. Kuyper, L. F. Lewis, G. E. Templeton, and S. H. Woodhead, Biochem. Biophys. Res. Commun. 56, 234-240 (1974).

[7] J. A. Steele, T. F. Uchytil, and R. D. Durbin, Biochim. Biophys. Acta 459, 347-350 (1977).

[8] J. A. Steele, R. D. Durbin, T. F. Uchytil, and D. H. Rich, Biochim. Biophys. Acta 501, 72-82 (1978 a).

[9] J. A. Steele, T. F. Uchytil, and R. D. Durbin, Biochim. Biophys. Acta 504, 136-141 (1978 b).

[10] J. A. Steele, T. F. Uchytil, R. D. Durbin, P. K. Bhatnagar, and D. H. Rich, Biochem. Biophys. Res. Commun. 84, 215-218 (1978c).

[11] U. Pick, P. L. Conrad, J. M. Conrad, R. D. Durbin, and B. R. Selman, Biochim. Biophys. Acta 682, $55-58$ (1982).
[12] W. Junge, G. Schoenknecht, and H. Lill, Progr. Photosynthesis Res. III, 2, 133-140 (1986).

[13] A. A. Bulychev and I. Dahse, Biochem. Physiol. Pfl. 179, 685-692 (1984).

[14] I. Dahse, A. A. Bulychev, G. A. Kurella, and B. Liebermann, Physiol. Plant. 65, 446-450 (1985).

[15] I. Dahse, D. M. Matorin, and B. Liebermann, Biochem. Physiol. Pfl. 181, 137-146 (1986).

[16] U. Pick and E. Racker, J. Biol. Chem. 254, 27932799 (1979).

[17] G. Schmidt and P. Gräber, Biochim. Biophys. Acta 808, 46-52 (1985).

[18] P. Fromme, E. J. Boekema, and P. Gräber, Z. Naturforsch. 42 c, 1239-1245 (1987).

[19] P. Fromme and P. Gräber, Biochim. Biophys. Acta 1016, 29-42 (1990).

[20] P. Gräber, E. Schlodder, and T. Witt, Biochim. Biophys. Acta 461, 426-440 (1977).

[21] B. R. Selman and S. Selman-Reimer, FEBS Lett. 97, 301-304 (1979).

[22] D. A. Harris, Biochim. Biophys. Acta 974, 156-162 (1989).

[23] U. Junesch and P. Gräber, Biochim. Biophys. Acta 893, 257-288 (1987). 